\title{
p53-dependent Fas expression is critical for Ginsenoside Rh2 triggered caspase-8 activation in HeLa cells
}

\author{
Xiao-Xi Guo ${ }^{1,2}$, Yang Li ${ }^{1}$, Chao Sun ${ }^{1}$, Dan Jiang ${ }^{1}$, Ying-Jia Lin ${ }^{1}$, Feng-Xie Jin $^{3}$, Seung-Ki Lee ${ }^{4}$, \\ Ying-Hua $\operatorname{Jin}^{1 \times}$ \\ ${ }^{1}$ Key Laboratory for Molecular Enzymology and Engineering of the Ministry of Education, College of Life Science, Jilin \\ University, Changchun 130012, China \\ 2 Faculty of Life Science and Technology, Kunming University of Science and Technology, Kunming 650500, China \\ ${ }^{3}$ College of Bio and Food Technology, Dalian Polytechnic University, Dalian 116034, China \\ ${ }^{4}$ College of Pharmacy and the Research Institute for Pharmaceutical Science, Seoul National University, Seoul 157-742, \\ Republic of Korea \\ $\triangle$ Correspondence: yhjin@jlu.edu.cn (Y.-H. Jin)
}

Received December 13, 2013 Accepted January 12, 2014

\begin{abstract}
We have recently reported that Ginsenoside Rh2 (G$\mathrm{Rh} 2$ ) induces the activation of two initiator caspases, caspase-8 and caspase-9 in human cancer cells. However, the molecular mechanism of its death-inducing function remains unclear. Here we show that G-Rh2 stimulated the activation of both caspase-8 and caspase-9 simultaneously in HeLa cells. Under G-Rh2 treatment, membrane death receptors Fas and TNFR1 are remarkably upregulated. However, the induced expression of Fas but not TNFR1 was contributed to the apoptosis process. Moreover, significant increases in Fas expression and caspase-8 activity temporally coincided with an increase in p53 expression in p53-nonmutated HeLa and SK-HEP-1 cells upon G-Rh2 treatment. In contrast, Fas expression and caspase-8 activity remained constant with G-Rh2 treatment in p53-mutated SW480 and PC-3 cells. In addition, siRNA-mediated knockdown of p53 diminished G-Rh2-induced Fas expression and caspase-8 activation. These results indicated that G-Rh2-triggered extrinsic apoptosis relies on p53-mediated Fas over-expression. In the intrinsic
\end{abstract}

Electronic supplementary material The online version of this article (doi:10.1007/s13238-014-0027-2) contains supplementary material, which is available to authorized users.

Xiao-Xi Guo and Yang Li contributed equally to this work. apoptotic pathway, G-Rh2 induced strong and immediate translocation of cytosolic BAK and BAX to the mitochondria, mitochondrial cytochrome $c$ release, and subsequent caspase-9 activation both in HeLa and in sW480 cells. p53-mediated Fas expression and subsequent downstream caspase-8 activation as well as p53-independent caspase-9 activation all contribute to the activation of the downstream effector caspase-3/-7, leading to tumor cell death. Taken together, we suggest that G-Rh2 induces cancer cell apoptosis in a multi-path manner and is therefore a promising candidate for antitumor drug development.

\section{KEYWORDS G-Rh2, Fas, p53, apoptosis}

\section{INTRODUCTION}

Apoptosis has been widely believed to play an important role in tissue development and homoeostasis maintenance. Dysregulation in the normal apoptotic process often leads to malignant transformation of cells (Favaloro et al., 2012; Brown and Attardi, 2005). In mammalian cells, apoptosis is initiated primarily by two pathways (Hengartner, 2000). The extrinsic apoptotic pathway involves the recruitment of death receptors, such as Fas and TNFR, by their specific ligands. The intrinsic apoptotic pathway depends on the depolarization of the mitochondrial outer membrane, which leads to the release of cytochrome $c$ and the activation of caspase-9 (van Loo et al., 2002). Current strategies in cancer chemotherapy 

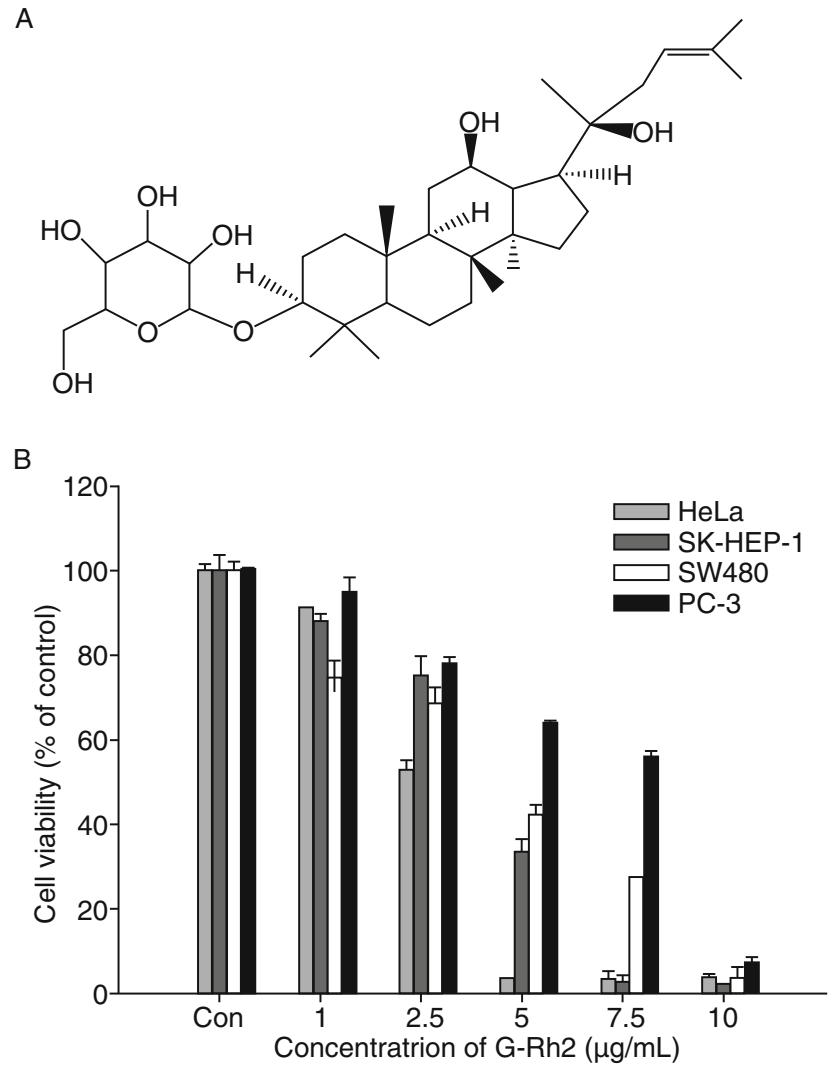

Figure 1. Dose-dependent antiproliferative effects of G-Rh2 on human cancer cells. (A) The chemical structure of G-Rh2. (B) HeLa, SK-HEP-1, SW480, and PC-3 cells were treated with G-Rh2 at different concentrations for $48 \mathrm{~h}$. The cell viability was determined by MTT assay. The results represent three independent experiments in triplicate. The values from each treatment are expressed as a percentage relative to the control $(100 \%)$. (mean $\pm \mathrm{SD})$.

mainly focus on triggering or restoring these two apoptotic signaling cascades (Wong, 2011).

G-Rh2, a ginseng saponin in the protopanaxadiol family isolated from the root of ginseng C.A. has been shown to have an anticancer effect on a variety of tumor cells (Odashima et al., 1985; Kim et al., 2000; Jin et al., 2000; Ham et al., 2003; Oh et al., 2005; Ham et al., 2006; Xie et al., 2006; Kim et al., 2007). Our recent study has shown that both caspase-8 and caspase- 9 were activated in G-Rh2 induced apoptosis of human hepatoma SK-HEP-1 cell (Guo et al., 2012). However, the exact molecular mechanisms of its pro-apoptotic functions remain poorly understood. In this study, we investigated two typical apoptotic pathways of G-Rh2-induced apoptosis in human cancer cell lines with different p53 mutation statuses. The data herein clearly showed that G-Rh2 triggers p53-dependent Fas expression and consequent activation of caspase-8 and p53-independent caspase-9-mediated intrinsic pathway to cause cancer cell death.
Table 1. The IC $\mathrm{I}_{50}$ values for $48 \mathrm{~h}$ treatment of G-Rh2 in cell lines with different p53 mutation status and caspase- 9 expression level

\begin{tabular}{llll}
\hline $\begin{array}{l}\text { Cell } \\
\text { line }\end{array}$ & $\begin{array}{l}\text { TP53 } \\
\text { status }\end{array}$ & $\begin{array}{l}\text { Caspase-9 } \\
\text { expression }\end{array}$ & $\begin{array}{l}\mathrm{IC}_{50} \\
(\mu \mathrm{g} / \mathrm{mL})^{*}\end{array}$ \\
\hline HeLa & WT & Normal & $2.52 \pm 0.05$ \\
SK-HEP-1 & WT & Low & $3.15 \pm 0.03$ \\
SW480 & MUT R273H & Normal & $4.06 \pm 0.02$ \\
PC-3 & MUT A138del & Low & $7.85 \pm 0.03$ \\
\hline
\end{tabular}

${ }^{*}$ mean $\pm \mathrm{SD}$ of three independent experiments.

\section{RESULTS}

G-Rh2 has an anti-proliferative effect on a variety of human cancer cells

The cytotoxic activity of G-Rh2 in the human tumor cell lines HeLa, SK-HEP-1, SW480, and PC-3 was assessed by MTT. Our previous study has shown that the expression of caspase-9 is significantly decreased in SK-HEP-1 and PC-3, and the expression of caspase- 9 influences cell sensitivity to cytotoxic drugs, such as betulin or etoposide, which induces apoptosis via initiated caspase-9/-3 activation pathway by mitochondrial cytochrome c release ( $\mathrm{Li}$ et al., 2010). Moreover, SW480 and PC-3 carry a mutant form of the p53 gene (Bamford et al., 2004; Nigro et al., 1989). The results (Fig. 1B, Table 1) showed that the cell viability of HeLa cells was remarkably inhibited by $\mathrm{G}-\mathrm{Rh} 2$, with an $\mathrm{IC}_{50}$ value of $2.52 \mu \mathrm{g} / \mathrm{mL}$, whereas SK-HEP-1 and SW480 cells were less sensitive to G-Rh2, with $\mathrm{IC}_{50}$ values of $3.15 \mu \mathrm{g} / \mathrm{mL}$ and 4.06 $\mu \mathrm{g} / \mathrm{mL}$, respectively. PC-3 cells were the least vulnerable to G-Rh2, with an $\mathrm{IC}_{50}$ value of $7.85 \mu \mathrm{g} / \mathrm{mL}$, 3-fold higher than HeLa cells.

Extrinsic and intrinsic pathways are simultaneously activated in G-Rh2-induced apoptosis

To acquire more insight into the pro-apoptotic process of G-Rh2, we investigated the caspase-8, -9 , and -3 activities in G-Rh2-treated HeLa cells in a time-dependent manner. We observed a notable increase in caspase-8 activity after $2 \mathrm{~h}$ G-Rh2 treatment, which occurred slightly earlier than that of caspase-9, which had an apparent rise $4 \mathrm{~h}$ after G-Rh2 treatment (Fig. 2A). The increase in caspase activity was also confirmed by Western blotting, which showed the cleavage of caspase- 8 and -9 (Fig. 2B). To examine the significance of the extrinsic and intrinsic pathways in G-Rh2induced apoptosis, we co-treated HeLa cells with G-Rh2 and specific peptide inhibitors for caspase-8 or caspase-9. Apoptosis progress was evaluated by determining cell morphology changes and caspase-3/-7 activation by PARP cleavage analysis. The data showed that cell apoptosis was remarkably attenuated by both caspase- 8 and caspase- 9 inhibitors compared with that in cells treated with G-Rh2 alone (Fig. 2C-E). All these results indicated that G-Rh2 
A

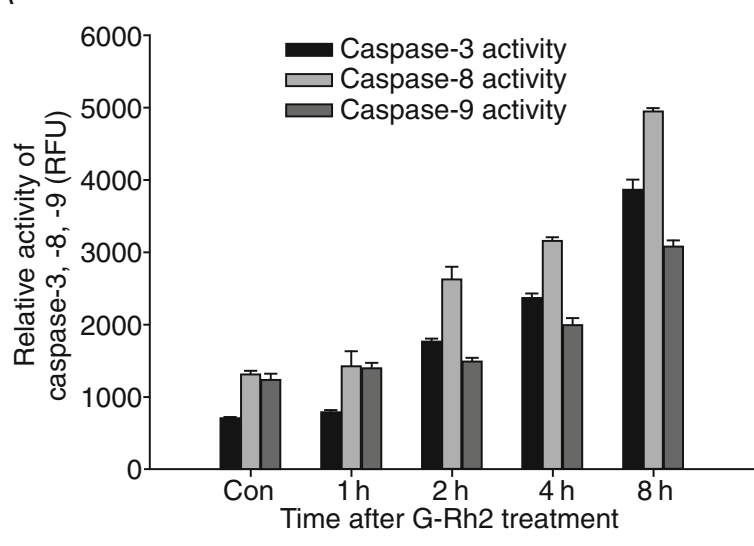

C

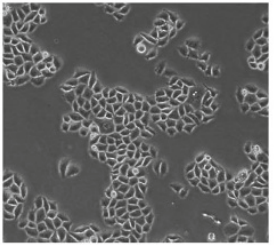

Control

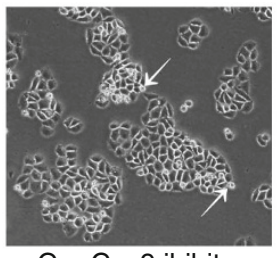

$\mathrm{G}+$ Cas9 ihibitor

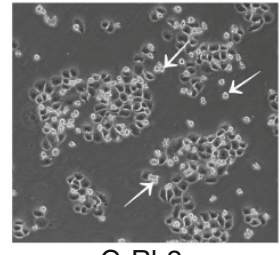

G-Rh2

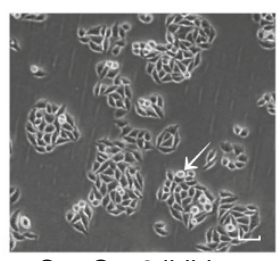

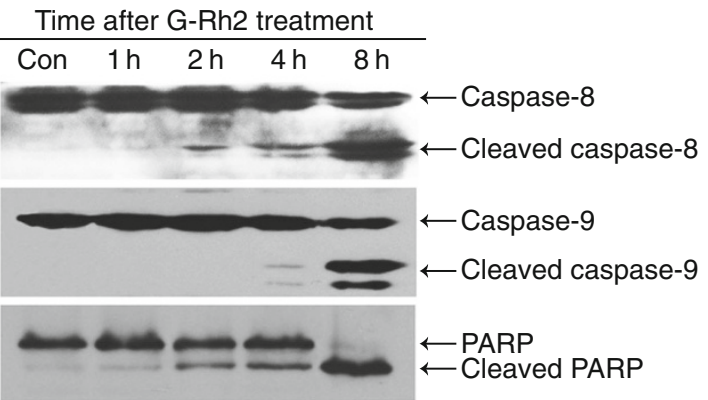

D

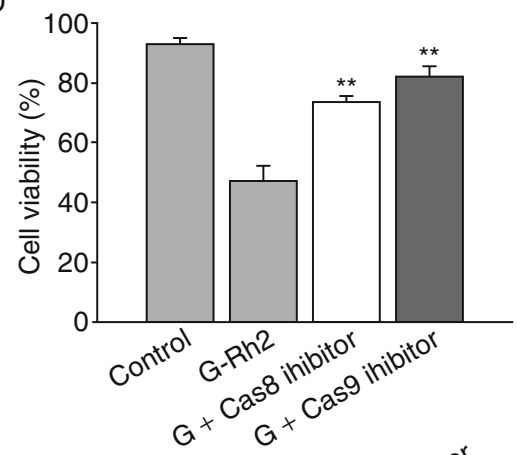

$\mathrm{E}$

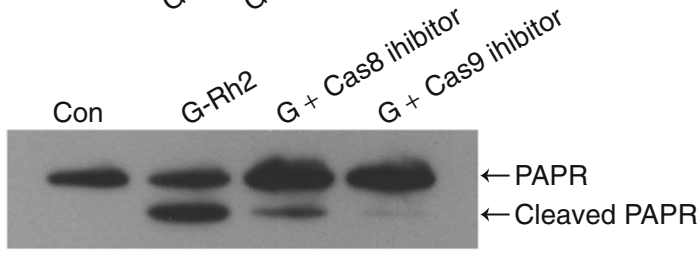

Figure 2. Caspases-8, -9 , and -3 were activated in G-Rh2-treated HeLa cells. (A-B) HeLa cells were treated with $7.5 \mu \mathrm{g} / \mathrm{mL}$ G-Rh2 for indicated times. (A) The cell-free caspase-3, -8, and -9 activities were analyzed using specific substrates. Values are reported as the mean \pm SEM of five experiments. (B) Equal amounts of cell extracts were analyzed by Western blotting. (C-E) HeLa cells were treated with G-Rh2 $(25 \mu \mathrm{g} / \mathrm{mL})$ or co-treated with G-Rh2 and caspase-8, or -9 inhibitor $(100 \mu \mathrm{mol} / \mathrm{L})$, in the presence of $2.5 \%$ serum for $8 \mathrm{~h}$. (C) The cell morphology changes were photographed using microscopy (50x) Significant differences: ${ }^{* \star} P<0.01$ compared with cells treated with G-Rh2 alone. The white arrows indicate blebbing cells undergoing apoptosis (bar, $50 \mu \mathrm{m})$. (D) The cell viability was determined by counting the blebbing and intact cells. The values from each treatment are expressed as an average proportion of intact cells in the total cell count (mean \pm SD of three independent experiments). (E) The apoptotic status of cells was confirmed by Western blotting using specific antibodies against PARP and its cleaved form. Lane 1 represents cells treated with G-Rh2 alone, lane 2 represents cells co-treated with G-Rh2 and caspase- 9 inhibitor, and lane 3 represents cells co-treated with G-Rh2 and caspase-8 inhibitor.

might have the unique ability to simultaneously and independently activate both caspase- 8 and caspase- 9 in HeLa cells.

\section{Fas and TNF-R1 are up-regulated in G-Rh2-treated HeLa cells}

To further explore the process of the death receptor-initiated caspase-8 activation pathways, which was rarely investigated in previous studies. First, we detected the mRNA levels, by using RT-PCR, of five typical death receptors, Fas, TNF-R1, TNF-R2, DR4, and DR5, and three corresponding ligands, FasL, TNF- $\alpha$, and TRAIL, in HeLa cells treated with $7.5 \mu \mathrm{g} / \mathrm{mL}$ G-Rh2 for $4 \mathrm{~h}$. The results showed that the mRNA levels of Fas, TNF- $\alpha$, TNF-R1, DR4, and DR5 were remarkably up-regulated after G-Rh2 treatment. No transcriptional changes were detected in FasL, TRAIL, and TNF-R2 (Fig. S1). We further examined the protein expression of Fas, FasL, TNF- $\alpha$, TNF-R1, DR4, and DR5 in HeLa cells upon G-Rh2 treatment by Western blotting. The data showed that the expression of Fas, TNF$\alpha$, and TNF-R1 were up-regulated by G-Rh2 in a timedependent manner, and the level of secreted FasL rose slightly. In addition, the expression of DR5 decreased but the expression of DR4 did not change with G-Rh2 treatment (Fig. 3A). 
A

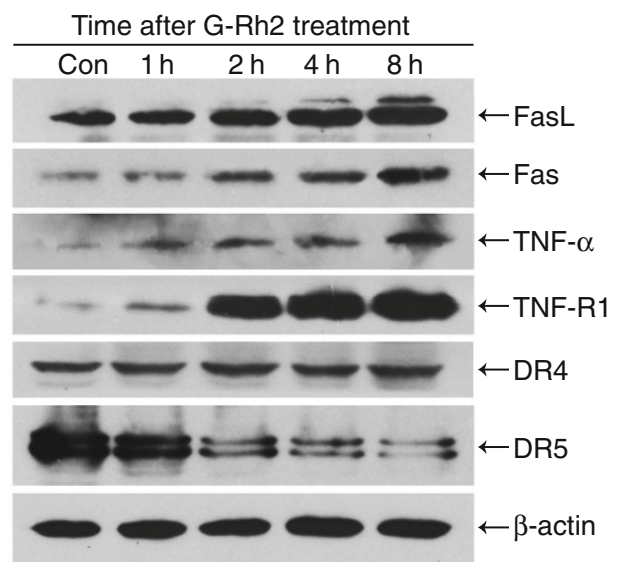

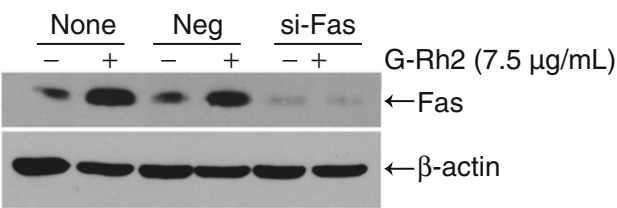

$\frac{\text { None }}{-+} \frac{\text { Neg }}{-+} \frac{\text { si-TNF-R1 }}{-+}$ G-Rh2 $(7.5 \mu \mathrm{g} / \mathrm{mL})$

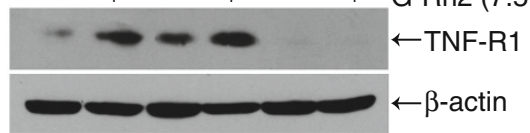

$\frac{\text { None }}{-+} \frac{\text { Neg }}{-+} \frac{\text { si-Fas }}{-+} \frac{\text { si-TNF-R1 }}{-+}$ G-Rh2 $(7.5 \mu \mathrm{g} / \mathrm{mL})$

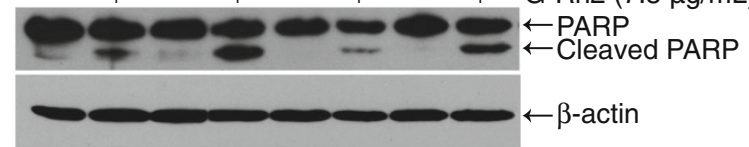

C
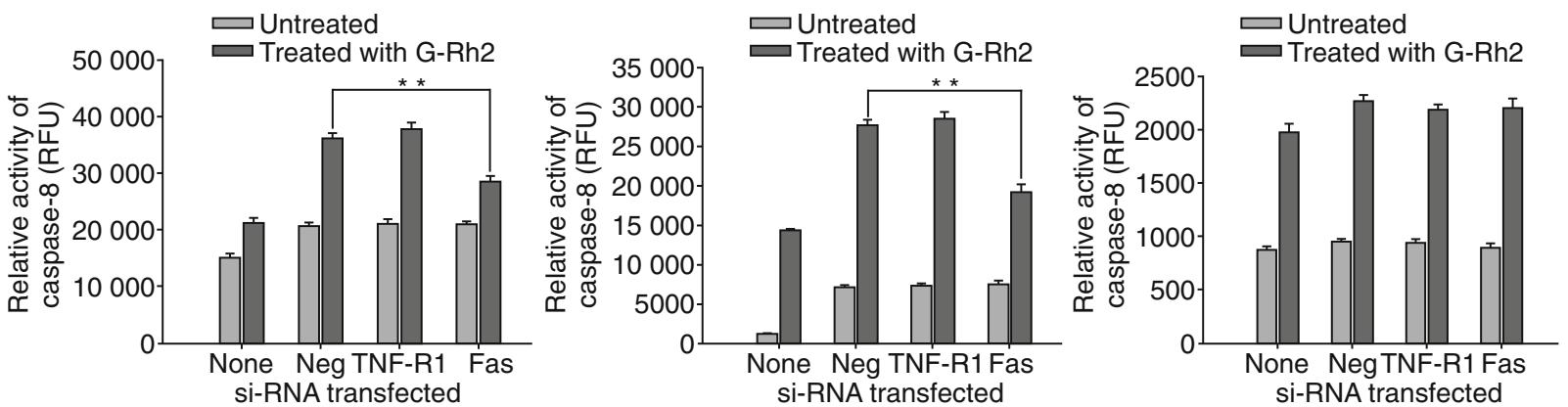

Figure 3. G-Rh2 induced the expression of death receptors and the apoptosis induced by G-Rh2 in HeLa cells is dependent on Fas. (A) HeLa cells were treated with $7.5 \mu \mathrm{g} / \mathrm{mL}$ G-Rh2 for indicated times. The cell lysates were analyzed by Western blotting. (B-C) HeLa cells were transfected with siRNA against Fas or TNF-R1 for $24 \mathrm{~h}$ before treatment with or without $7.5 \mu \mathrm{g} / \mathrm{mL}$ G-Rh2 for 6 h. Non-transfected cells and cells transfected with negative control RNA duplex served as controls. (B) Cell lysates were analysed by Western blotting. (C) The activity of caspase-8, -9 , and -3 were determined as described in MATERIALS AND METHODS (Asterisks represent statistical significant differences with negative control, ${ }^{* *} P<0.01$ ).

Fas is the key factor for caspase-8 activation in G-Rh2induced apoptosis

Because our data suggested that the pro-apoptotic function of G-Rh2 might largely depend on the up-regulation of Fas and TNF-R1, we examined the Fas or TNF-R1-mediated caspase-8 activation cascade by, respectively, silencing Fas or TNF-R1 via using small interfering RNAs against them in HeLa cells. After silencing either Fas or TNF-R1, the cells were treated with $7.5 \mu \mathrm{g} / \mathrm{mL}$ G-Rh2 for $6 \mathrm{~h}$. The expression of Fas and TNF-R1 and PARP cleavage was determined by Western blotting and caspase-8, -9 , and -3 activities were assayed. The results showed that the silencing of Fas significantly attenuated caspase- 8 and caspase- 3 activation and PARP cleavage, whereas silencing of TNF-R1 seemed to have no effect on G-Rh2-induced apoptosis. Meanwhile, caspase- 9 activities were not influenced by either Fas or TNF-R1 silencing (Fig. 3B and 3C).

\section{G-Rh2-induced Fas expression is mediated by p53}

Mutations in p53 genes occur in a large number of cancer cells (Bamford et al., 2004; Nigro et al., 1989; Zalcenstein et al., 2003), causing the resistance of cancer cells to antitumor reagents. A number of studies have been reported that the expression of the death receptor Fas (CD95) is controlled by wild-type p53 (Ham et al., 2003; Zalcenstein et al., 2003; Owen-Schaub et al., 1995; de la Monte et al., 1997; Takahashi, 1997; Müller et al., 1998; Embree-Ku et al., 2002; Schilling et al., 2009). Considering these facts and our experimental results, we hypothesized that Fas upregulation after G-Rh2 treatment in human cancer cells might be related to p53 status. To examine this idea, we investigated Fas expression and caspase-8 activation upon G-Rh2 treatment in human cancer cells with wild type or mutated version of $\mathrm{p} 53$. The results showed that after treatment with G-Rh2, significant increases in Fas expres- 
A

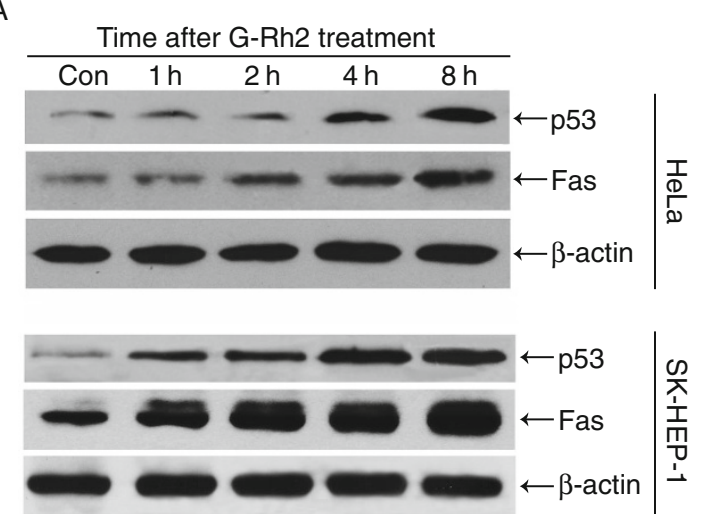

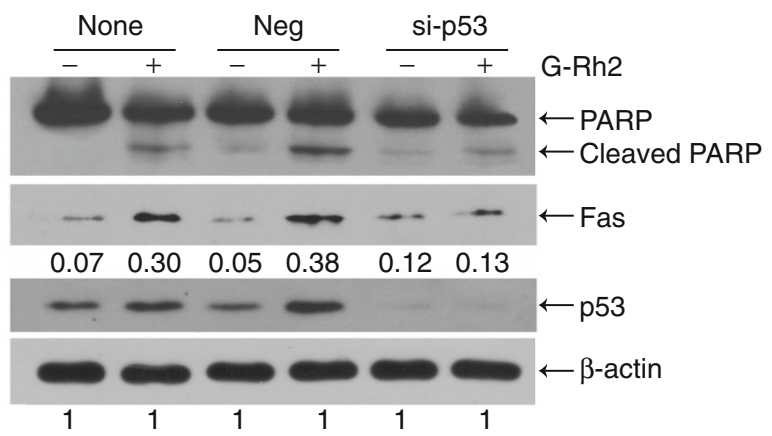

D

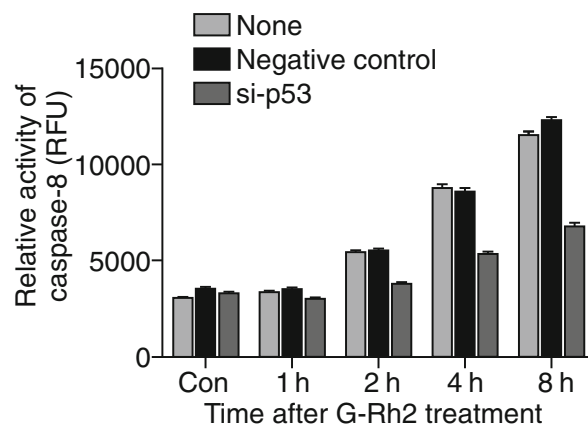

E

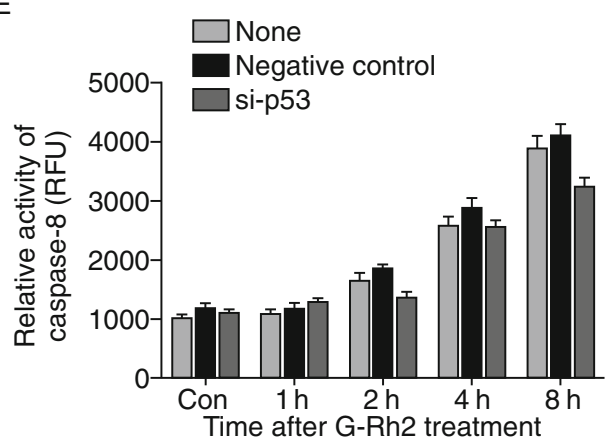

Figure 4. G-Rh2 induces p53-dependent Fas expression in cancer cells. (A) HeLa, SK-HEP-1, SW480, and PC-3 cells were treated with $7.5 \mu \mathrm{g} / \mathrm{mL}$ G-Rh2 for indicated times. The cell lysates were analyzed by Western blotting. (B) Caspase-8 activities of four cell lines were determined at indicated time points. (C) HeLa cells were transfected with a siRNA against p53 for $24 \mathrm{~h}$ before treatment with or without $7.5 \mu \mathrm{g} / \mathrm{mL}$ G-Rh2 for $6 \mathrm{~h}$. Non-transfected cells and cells transfected with negative control RNA duplex served as controls. The cell lysates were analyzed by Western blotting. The numbers below the Fas bands represent each band's relative abundance to the loading controls, which was quantified by Image-Pro Plus software. (D) HeLa cells were transfected with a siRNA against p53 for $24 \mathrm{~h}$ before treatment with or without $7.5 \mu \mathrm{g} / \mathrm{mL} \mathrm{G-Rh} 2$ for $6 \mathrm{~h}$ and caspase- 8 and -9 activities were determined as described in MATERIALS AND METHODS.

sion and caspase- 8 activity coincided with an increase in p53 expression in p53-non-mutated HeLa and SK-HEP-1 cells. In contrast, Fas expression and caspase-8 activity remained constant with G-Rh2 treatment in p53-mutated SW480 and PC-3 cells (Fig. 4A and 4B). Moreover, p53 expression in these four cell lines increased in varying degrees, which suggests G-Rh2 may act as a stabilizer for p53 (Fig. 4A). The relationship between p53 and G-Rh2- induced Fas up-regulation in p53-silenced HeLa cells was also confirmed by Western blotting. As shown in Fig. 4C and 4D, G-Rh2-induced Fas up-regulation, caspase-8 activation, and PARP cleavage were remarkably attenuated in p53-silenced HeLa cells, compared with that of cells transfected with negative control siRNAs. Interestingly, the activation of caspase- 9 seems to be not significantly influenced by 553 silencing (Fig. 4E) 

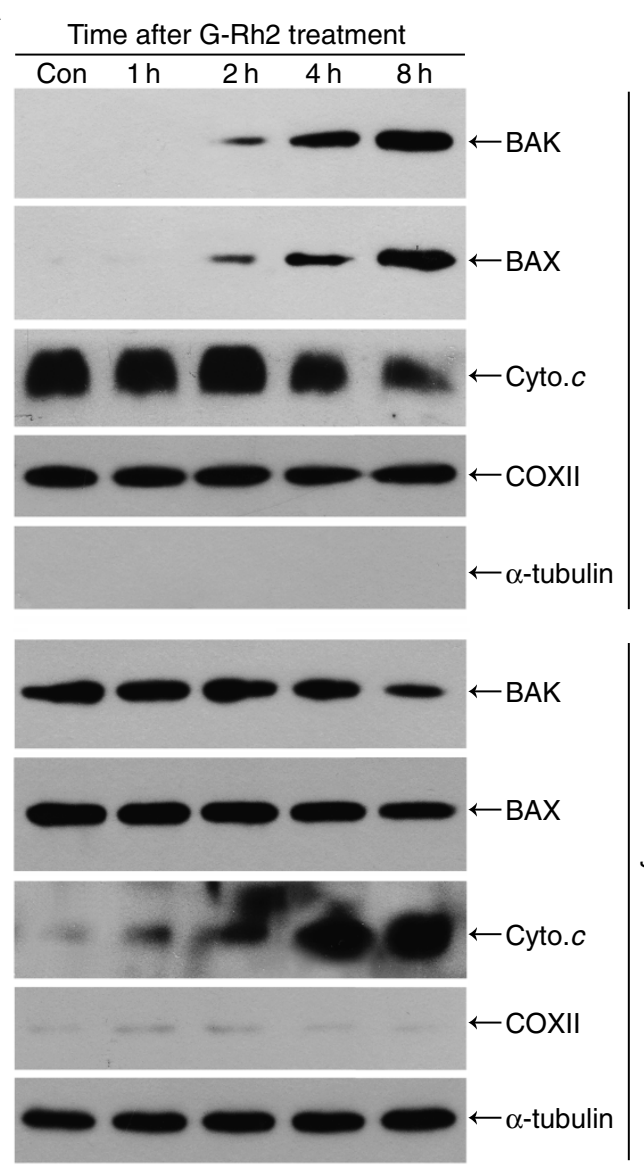

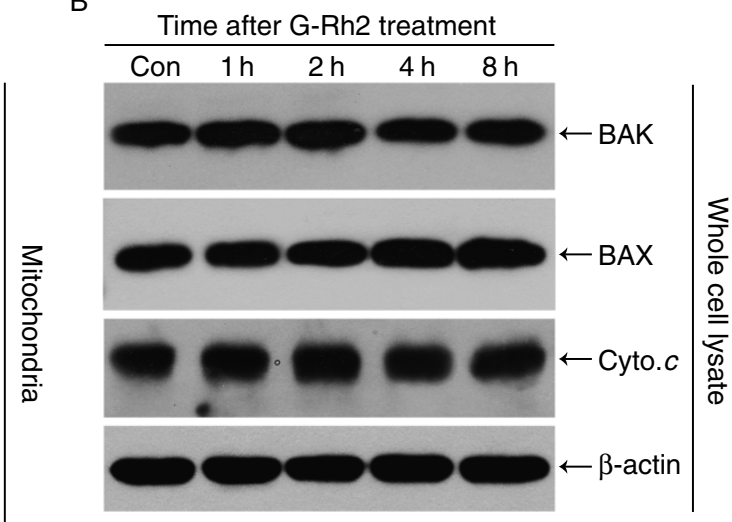

C
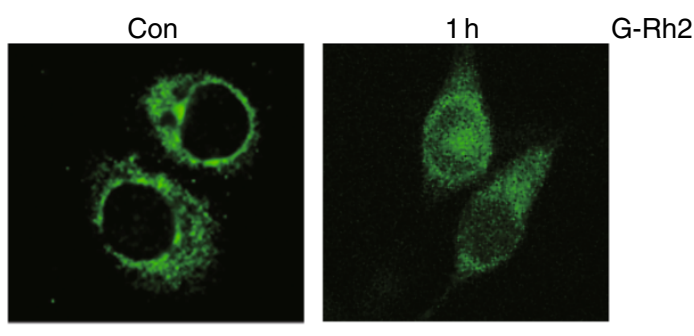

Figure 5. G-Rh2 triggers the translocation of BAX and BAK, and cytochrome c release in HeLa cells. HeLa cells were treated with $7.5 \mu \mathrm{g} / \mathrm{mL}$ G-Rh2 at indicated times. The cell fractions were isolated as described in MATERIALS AND METHODS. The (A) mitochondrial, and cytosolic fractions, and (B) total cell lysate were analyzed by Western blotting for BAK, BAX, cytochrome c, COX II, a-tubulin, and $\beta$-actin. (C) The cells were fixed and stained with anti-cytochrome $c$ antibodies and analyzed by fluorescence microscope using appropriate filters for the visualization of green fluorescence resulting from the presence of FITC molecules.

Mitochondrial-mediated caspase-9 activation

in both p53 wild type HeLa cells and p53-mutated SW480 cells

To gain more insight into the mechanism of G-Rh2-induced apoptosis, we examined the mitochondrial-mediated intrinsic pathway in HeLa cells. We treated HeLa cells with G-Rh2 for indicated times. Cell fractions were isolated and examined by Western blotting. The results demonstrated that the levels of mitochondrial BAK and BAX began to notably increase at $2 \mathrm{~h}$ after G-Rh2 treatment (Fig. 5A); at the same time, the levels of cytosolic cytochrome $\mathrm{c}$ increased in a similar time-dependent manner. In contrast, the levels of cytosolic BAK and BAX, and mitochondrial cytochrome $\mathrm{c}$ decreased in a time-dependent manner (Fig. 5A). However, the levels of total BAK and cytochrome c remained constant, whereas BAX was slightly upregulated during this process (Fig. $5 \mathrm{~B}$ ). Immunostaining analysis also showed that cytochrome $\mathrm{c}$ remarkably released from mitochondria upon G-Rh2 treatment (Fig 5C). These data implied that G-Rh2 effectively provoked the translocation of the pro-apoptotic proteins BAK and BAX from the cytosol to the mitochondria in HeLa cells, which in turn consequently induced cytochrome $c$ release from the mitochondria to the cytosol (Fig. 5A and 5B), and therefore activated caspase-9 (Fig. 2A and 2B).

We also investigated the intrinsic apoptosis pathway in p53-mutated SW480 cells. The results demonstrated that the levels of mitochondrial BAK and BAX began to notably increase at $2 \mathrm{~h}$ after G-Rh2 treatment (Fig. 6A); at the same time, we detected, by $\mathrm{JC}-1$ staining, the dissipation of mitochondrial membrane potential in G-Rh2 treated SW480 cells (Fig. 6B), which were coincident with the increase of cytosolic cytochrome c (Fig. 6A). Similar with HeLa cells, under the treatment of G-Rh2, the expression level of whole-cell BAK and cytochrome c remained constant. But different from the results of HeLa cells, the 
A

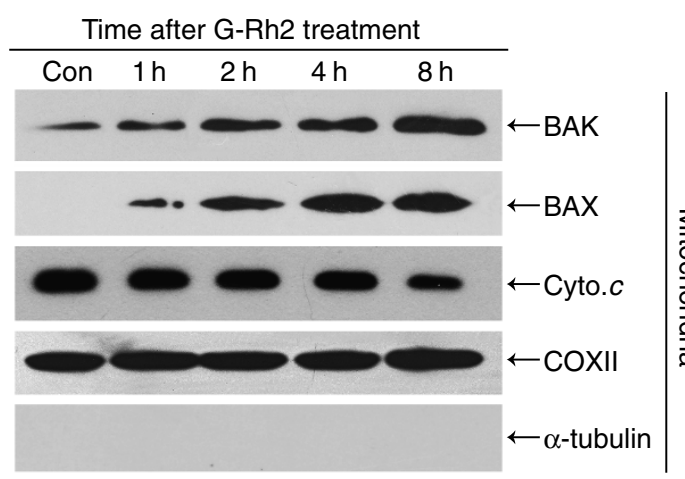

B

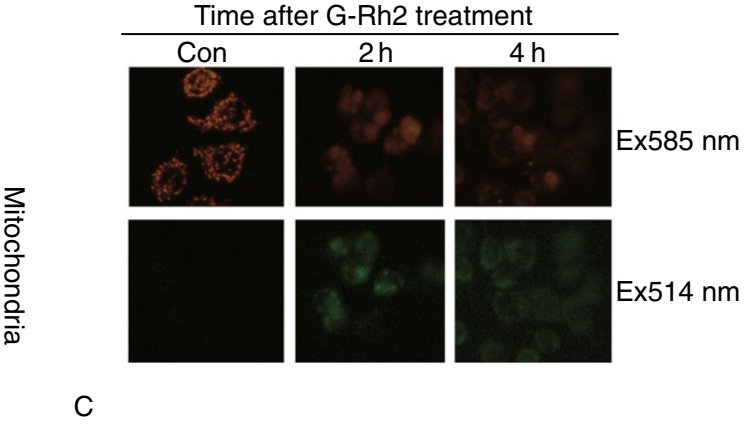

C

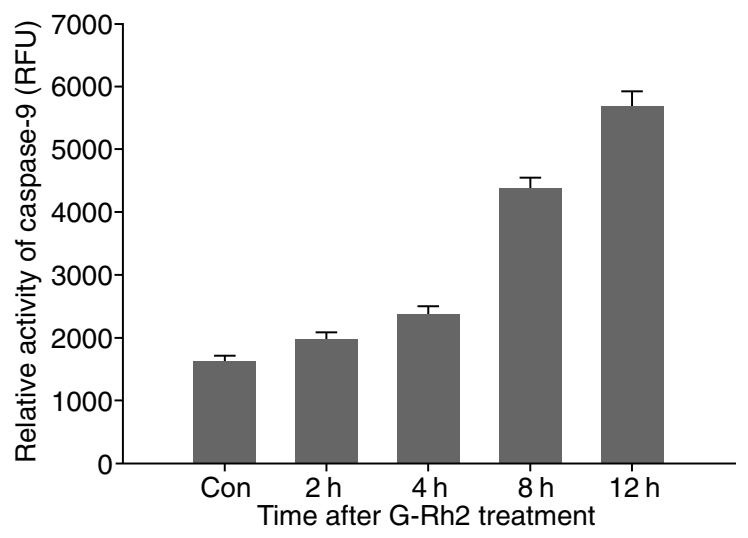

Figure 6. G-Rh2 triggers the translocation of BAX and BAK, cytochrome c release, and consequently activation of caspase9 in SW480 cells. SW480 cells were treated with $7.5 \mu \mathrm{g} / \mathrm{mL}$ G-Rh2 at indicated times. The cell fractions were isolated as described in MATERIALS AND METHODS. (A) The mitochondrial and cytosolic fractions and total cell lysate were analyzed by Western blotting. (B) G-Rh2-induced dissipation of $\Delta \Psi \mathrm{m}$ in SW480 cells. Red fluorescence represents the mitochondrial aggregate form of JC-1, indicating intact mitochondrial membrane potential. Green fluorescence represents the monomeric form of JC-1, indicating dissipation of $\Delta \Psi \mathrm{m}$. (C) At various time points, caspase-9 activity was assayed as described in MATERIALS AND METHODS. Values are reported as the mean \pm SEM of five experiments.

whole-cell BAX levels did not change, which may due to the loss of transcriptional function of mutated p53 in SW480 cells (Figs. 5 and $6 \mathrm{~A}$ ). These data implied that G-Rh2 effectively provoked the translocation of the proapoptotic proteins BAK and BAX from the cytosol to the mitochondria in SW480 cells, which in turn promoted the depolarization of mitochondria and consequently induced cytochrome $c$ release from the mitochondria to the cytosol, and therefore activated caspase-9 (Fig. 6C), similar to that observed in G-Rh2-treated HeLa cells (Fig. 5). In contrast, caspase-8 was not activated during this process (Fig. 4B), indicating that, in SW480 cells, mutated p53 disables Fas upregulation and prevents the activation of caspase- 8 . These results implied that G-Rh2-induced cytochrome c release and caspase-9 activation is independent on p53related and/or Fas-initiated caspase-8 activation.

\section{DISCUSSION}

For decades, anti-cancer compounds have been developed to target specific apoptosis-related proteins in certain signaling pathways. However, the expression of apoptosisrelated genes varies widely in carcinoma cells, which gives cancer cells various sensitivities to anti-tumor drugs (Brown and Wilson, 2003; Galmarini and Galmarini, 2003; Liu, 2009). In this sense, multi-target drugs capable of triggering multiple apoptotic pathways will be ideal candidates for chemotherapy. Frequent down-regulation of the death receptor Fas (CD95) aids in apoptotic-escape of cancer cells, thereby promoting cancer progression and tumor evasion (Debatin and Krammer, 2004; Peter et al., 2005).

For the first time, we have shown that G-Rh2 induces apoptosis in human cancer cells by activating both extrinsic 
and intrinsic apoptosis pathways (Fig. 2). Activation of the extrinsic pathway by G-Rh2 significantly induced the overexpression of the death receptor Fas in a wild-type p53dependent manner and thus, resulted in caspase- 8 activation (Fig. 3). In agreement with our findings, a previous study observed that G-Rh2 induced Fas oligomerization in HeLa cells (Yi et al., 2009). Fas expression might reinforce the immune privilege of apoptosis-resistant tumor cells, which, in most cases, express low levels of Fas and thus, cannot sufficiently respond to apoptotic signal brought about by FasL in immune cells (Nagata, 1999; Strasser et al., 2009; Zhou et al., 1998). We also observed that p53 was up-regulated in targeted cells upon G-Rh2 treatment (Fig. 4A), which implies that G-Rh2 might increase the stability of p53 and prevent the ubiquitin-mediated degradation of p53 (Brooks and Gu, 2003).

Although another death receptor, TNF-R1, and its ligand, TNF- $\alpha$, were also up-regulated after G-Rh2 treatment in HeLa cells, the increase in expression did not seem to contribute to G-Rh2-induced apoptosis (Fig. 3). TNFR1 is involved in death signalling; however, TNF-induced cell death only plays a minor role, compared to its overwhelming functions, in the inflammatory process. Its death-inducing capability is often masked by the anti-apoptotic effects of NFKB (Gaur and Aggarwal, 2003). In any case, further investigation is warranted.

Activation of the intrinsic pathway mediated by G-Rh2 triggers caspase- 9 activation by promoting strong and immediate translocation of both BAX and BAK from the cytosol to the mitochondria and, consequently, the release of cytochrome $c$ from the mitochondria. Different from previous reports (Li et al., 2011; Kim and Jin, 2004), G-Rh2-induced mitochondrial pathway appeared not to be mediated by p53-dependent Bax overexpression in HeLa cells. The protein levels of Bax were not notably increased after G-Rh2 treatment (Fig. 5B) and the silencing of p53 did not attenuate the early stage activation of caspase-9 in G-Rh2 treated HeLa cells (Fig. 4E).

p53 genes are mutated in more than $50 \%$ of human cancer cell lines, which results in chemoresistance of those cell lines (Bamford et al., 2004; Kawamata et al., 2007; Andrews et al., 2004; Cappello et al., 2002). Importantly, G-Rh2 induced effective apoptotic cell death even in the p53-mutated cancer cell line SW480 via mitochondrial BAX and BAK translocation, which initiated the caspase-9 pathway (Fig. 6).

Taken together, the multi-path pro-apoptotic function and the unique capability of reinforcing the Fas/FasL pathway suggest that G-Rh2 may be a promising anti-tumor drug candidate. However, we found that G-Rh2 interacts with serum BSA (Data not shown) and its activity is attenuated by presence of serum (Li et al., 2011). Therefore, it is important to overcome the effect of serum in G-Rh2 based drug development. It will be also important to identify the precise cellular targets of G-Rh2, which may help to elucidate the mechanism of its anti-tumor functions and contribute to the development of more effective anticancer drugs.

\section{MATERIALS AND METHODS}

\section{Cell culture}

HeLa, SK-HEP-1, SW480, and PC-3 cells were grown in Dulbecco's Modified Eagle's Medium (DMEM) supplemented with $10 \%$ heatinactivated calf serum, $100 \mu \mathrm{g} / \mathrm{mL}$ of penicillin, and $100 \mu \mathrm{g} / \mathrm{mL}$ of streptomycin at $37^{\circ} \mathrm{C}$ in a humidified atmosphere containing $5 \%$ $\mathrm{CO}_{2}$.

\section{Determination of cell viability by MTT assay}

Determination of cell viability was performed by using MTT assay (Sigma, St. Louis, MO), which was used to calculate the growth inhibition induced by increasing concentrations of drug. Briefly, exponentially growing cells were seeded into a 96-well plate at $1 \times$ $10^{4}$ cells/well in triplicate. After incubation for $24 \mathrm{~h}$, cells were treated with increasing concentration of G-Rh2 in serum free media for $48 \mathrm{~h}$. At the end of treatment, $20 \mu \mathrm{L}$ of MTT $(5 \mathrm{mg} / \mathrm{mL})$ was added to each well and incubated for an additional $4 \mathrm{~h}$. The formazan grains formed by viable cells were solubilized with DMSO, and the color intensity was measured at $550 \mathrm{~nm}$ with an ELISA reader (BioTek Instruments, Winooski, VT).

\section{RNA purification and Reverse Transcription-PCR}

Total RNA was isolated from HeLa cells with Tri Reagent (Molecular Research Centre, Inc. Cincinnati, $\mathrm{OH}$ ) according to the manufacturer's instructions. RNA was reverse-transcribed with an RNA PCR Kit (AMV, Takara Biotechnology, Dalian, China) and the supplied oligo dT primer using a thermal program of $42^{\circ} \mathrm{C}$ for $30 \mathrm{~min}, 99^{\circ} \mathrm{C}$ for $5 \mathrm{~min}$, and $5^{\circ} \mathrm{C}$ for 5 min. Transcribed poly (A) RNA of pSPTet3 plasmid was used as a positive control RNA. PCR reactions were performed with Taq polymerase (Takara Biotechnology, Dalian, China) using the primers shown in Table S1. Supplied primers to $\beta$-actin were used to determine the mRNA level of $\beta$-actin, which served as an internal reference. PCR products were resolved on $1.5 \%$ agarose gels and visualized with ethidium bromide under ultraviolet light.

Preparation of total protein in cell lysates

G-Rh2-treated cells in serum free media were washed with PBS, and cell pellets were re-suspended in lysis buffer containing 20 $\mathrm{mmol} / \mathrm{L}$ Tris, $\mathrm{pH} 7.5,0.5 \%$ Triton X-100, $2 \mathrm{mmol} / \mathrm{L} \mathrm{MgCl}, 1 \mathrm{mmol} / \mathrm{L}$ DTT, $1 \mathrm{mmol} / \mathrm{L}$ EGTA, $50 \mathrm{mmol} / \mathrm{L} \beta$-glycerol phosphate, $25 \mathrm{mmol} / \mathrm{L}$ $\mathrm{NaF}, 1 \mathrm{mmol} / \mathrm{L} \mathrm{Na}_{3} \mathrm{VO}_{4}, 2 \mathrm{mg} / \mathrm{mL}$ leupeptin, $2 \mathrm{mg} / \mathrm{mL}$ pepstatin A, 2 $\mathrm{mg} / \mathrm{mL}$ antipain, and $1 \mathrm{mmol} / \mathrm{L}$ PMSF for $1 \mathrm{~h}$. The lysates were centrifuged at $12000 \mathrm{rpm}$ for $15 \mathrm{~min}$, and the supernatants were recovered for further protein analysis.

\section{Caspase activity assay}

HeLa, SK-HEP-1, SW480, and PC-3 cells were treated with G-Rh2 (7.5 $\mu \mathrm{g} / \mathrm{mL})$ in serum free media for indicated time periods and then were harvested. Fifty micrograms of cell lysates were incubated with 200 $\mathrm{nmol} / \mathrm{L}$ Ac-DEVD-AFC (for caspase-3), Ac-IETD-AFC (for caspase-8), and Ac-LEHD-AFC (for caspase-9) in a reaction buffer containing 20 $\mathrm{mmol} / \mathrm{L}$ HEPES, $\mathrm{pH} 7.4,100 \mathrm{mmol} / \mathrm{L} \mathrm{NaCl}, 10 \mathrm{mmol} / \mathrm{L} \mathrm{DTT}, 0.1 \%$ 
CHAPS, and $10 \%$ sucrose at $37^{\circ} \mathrm{C}$ for $1 \mathrm{~h}$. The reaction was monitored by fluorescence emission at $535 \mathrm{~nm}$ and excitation at $405 \mathrm{~nm}$.

\section{JC-1 staining and $\Delta \Psi \mathrm{m}$ measurement}

Loss of mitochondrial membrane potential $\left(\Delta \Psi_{\mathrm{m}}\right)$ was assessed by fluorescence microscope (IX71, Olympus) by JC-1 (Beyotime, China) staining. SW480 cells were stained with $\mathrm{JC}-1$ for $20 \mathrm{~min}$ at $37^{\circ} \mathrm{C}$ after incubation with G-Rh2 $(7.5 \mu \mathrm{g} / \mathrm{mL})$ in serum free media for indicated times. The fluorescence was detected with a microplate reader (Tecan infinite 200). The wavelengths of excitation and emission were $514 \mathrm{~nm}$ and $529 \mathrm{~nm}$ respectively for detection of monomeric form of JC-1. $585 \mathrm{~nm}$ and $590 \mathrm{~nm}$ were used to detect aggregation of JC-1. Red emission of the dye represented a potential-dependent aggregation in the mitochondria, reflecting $\Delta \Psi_{\mathrm{m}}$. Green fluorescence represented the monomeric form of $\mathrm{JC}-1$, appearing in the cytosol after mitochondrial membrane depolarization.

Preparation of mitochondrial and cytosolic extracts

Preparation of mitochondrial and cytosolic extracts was performed using the Mitochondria Isolation Kit (Pierce Biotechnology, Rockford, IL) for cultured cells according to the manufacturer's instructions. Isolated mitochondria were solubilized in lysis buffer containing 20 $\mathrm{mmol} / \mathrm{L}$ Tris, $\mathrm{pH} 7.5,0.5 \%$ Triton X-100, $2 \mathrm{mmol} / \mathrm{L} \mathrm{MgCl} 2,1 \mathrm{mmol} / \mathrm{L}$ DTT, $1 \mathrm{mmol} / \mathrm{L}$ EGTA, $50 \mathrm{mmol} / \mathrm{L} \beta$-glycerol phosphate, $25 \mathrm{mmol} / \mathrm{L}$ $\mathrm{NaF}, 1 \mathrm{mmol} / \mathrm{L} \mathrm{Na}_{3} \mathrm{VO}_{4}, 2 \mathrm{mg} / \mathrm{mL}$ leupeptin, $2 \mathrm{mg} / \mathrm{mL}$ pepstatin $\mathrm{A}, 2$ $\mathrm{mg} / \mathrm{mL}$ antipain, and $1 \mathrm{mmol} / \mathrm{L}$ PMSF for $1 \mathrm{~h}$. The lysate was centrifuged at $12000 \mathrm{rpm}$ for $15 \mathrm{~min}$, and the supernatant containing the mitochondrial extract was collected.

\section{Western blotting analysis}

Antibodies against cytochrome c, poly (ADP-ribose) polymerase (PARP), and $\beta$-actin were purchased from Santa Cruz Biotechnology. Antibodies against caspase-8, caspase-9, Fas, TNFR1, TNF- $\alpha$, DR4, DR5, and p53 were purchased from Abcam (Hong Kong). Horseradish peroxidase (HRP)-conjugated secondary antibodies were purchased from Pierce Biotechnology. Equal amounts of cell lysates were separated by SDS-PAGE and electrotransferred onto immobilon transfer membranes (Millipore, Bedford, MA). The membranes were blocked with $5 \%$ skim milk and probed with the indicated antibodies. The blots were washed and incubated with an HRP-coupled anti-mouse or anti-rabbit IgG antibody, followed by detection with ECL-enhanced chemiluminescence detection reagents (Amersham Biosciences, Piscataway, NJ). $\beta$-actin, $\alpha$ tubulin or COXII were used as loading controls.

\section{RNA interference}

siRNA duplexes for Fas, TNF-R1, p53, and non-targeting negative control siRNA were purchased from Bioneer. The siRNA sequences are listed in Table S2. $3 \times 10^{5} \mathrm{HeLa}$ cells in six-well dishes were transfected with a final concentration of $75 \mathrm{nmol} / \mathrm{L}$ siRNA duplexes using HiPerFect Transfection Reagent (Qiagen, Valencia, CA) according to the manufacturer's instructions. After incubation for 24 $\mathrm{h}$, the cells were treated with G-Rh2 $(7.5 \mu \mathrm{g} / \mathrm{mL})$ in serum free media for $6 \mathrm{~h}$. Finally, the total protein in the cell lysates was prepared for caspase activity assay and Western blotting analysis of Fas, TNF$\mathrm{R} 1, \mathrm{p} 53, \beta$-actin, and PARP.

\section{Immunostaining analysis}

The cells were cultured overnight on sterile glass cover slips in 24-well plates. The cells were treated with G-Rh2 $(7.5 \mu \mathrm{g} / \mathrm{mL})$ for $2 \mathrm{~h}$ to induce apoptosis and subsequently fixed with $95 \%$ ethanol for $20 \mathrm{~min}$, rinsed three times with PBS, and permeabilized with $0.2 \%$ Triton X-100 for 15 $\mathrm{min}$. The cells were again rinsed three times with PBS, blocked for 45 min with blocking solution ( $5 \% \mathrm{BSA}$ ), and then rinsed with PBS. The cells were incubated for $3 \mathrm{~h}$ with primary antibodies specific to mouse monoclonal anti-cytochrome $c(1: 100)$. The cells were rinsed three times in PBS and incubated in secondary antibody (FITC-conjugated goat anti-mouse secondary antibody, 1:300). The cells were washed twice in PBS and then mounted by inverting onto mounting medium on glass slides. The slides were stored at $4^{\circ} \mathrm{C}$ and analyzed by fluorescence microscope (Olympus).

\section{ACKNOWLEDGEMENTS}

This work was supported by grants from the National Nature Science Foundation of China (Grant Nos. 31240078 and 31070670).

\section{ABBREVIATIONS}

G-Rh2, Ginsenoside Rh2; MTT, 3-(4,5-dimethylthiazol-2-yl)-2,5diphenyltetrazoniumbromide; PARP, poly(ADP-ribose)polymerase; siRNA, small interfering RNA.

\section{COMPLIANCE WITH ETHICS GUIDELINES}

Xiao-Xi Guo, Yang Li, Chao Sun, Dan Jiang, Ying-Jia Lin, Feng-Xie Jin, Seung-Ki Lee,Ying-Hua Jin declare that they have no conflict of interest.

This article does not contain any studies with human or animal subjects performed by the any of the authors.

\section{OPEN ACCESS}

This article is distributed under the terms of the Creative Commons Attribution License which permits any use, distribution, and reproduction in any medium, provided the original author(s) and the source are credited.

\section{REFERENCES}

Andrews GA, Xi SC, Pomerantz RG, Lin CJ, Gooding WE, Wentzel AL, Wu L, Sidransky D, Grandis JR (2004) Mutation of p53 in head and neck squamous cell carcinoma correlates with $\mathrm{Bcl}-2$ expression and increased susceptibility to cisplatin-induced apoptosis. Head Neck 26:870-877

Bamford S, Dawson E, Forbes S, Clements J, Pettett R, Dogan A, Flanagan A, Teague J, Futreal PA, Stratton MR, Wooster R (2004) The COSMIC (Catalogue of Somatic Mutations in Cancer) database and website. Br J Cancer 91:355-358

Brooks CL, Gu W (2003) Ubiquitination, phosphorylation and acetylation: the molecular basis for p53 regulation. Curr Opin Cell Biol 15:164-171 
Brown JM, Attardi LD (2005) The role of apoptosis in cancer development and treatment response. Nat Rev Cancer 5:231237

Brown JM, Wilson G (2003) Apoptosis genes and resistance to cancer therapy: what does the experimental and clinical data tell us? Cancer Biol Ther 2:477-490

Cappello F, Bellafiore M, Palma A, Bucchieri F (2002) Defective apoptosis and tumorigenesis: role of p53 mutation and Fas/FasL system dysregulation. Eur J Histochem 46:199-208

de la Monte SM, Sohn YK, Wands JR (1997) Correlates of p53- and Fas (CD95)-mediated apoptosis in Alzheimer's disease. J Neurol Sci 152:73-83

Debatin KM, Krammer PH (2004) Death receptors in chemotherapy and cancer. Oncogene 23:2950-2966

Embree-Ku M, Venturini D, Boekelheide K (2002) Fas is involved in the p53-dependent apoptotic response to ionizing radiation in mouse testis. Biol Reprod 66:1456-1461

Favaloro B, Allocati N, Graziano V, Di llio C, De Laurenzi V (2012) Role of apoptosis in disease. Aging 4:330-349

Galmarini CM, Galmarini FC (2003) Multidrug resistance in cancer therapy: role of the microenvironment. Curr Opin Investig Drugs 4:1416-1421

Gaur U, Aggarwal BB (2003) Regulation of proliferation, survival and apoptosis by members of the TNF superfamily. Biochem Pharmacol 66:1403-1408

Guo XX, Guo Q, Li Y, Lee SK, Wei XN, Jin YH (2012) Ginsenoside Rh2 induces human hepatoma cell apoptosis via Bax/Bak triggered cytochrome $C$ release and caspase-9/caspase-8 activation. Int J Mol Sci 22:15523-15535

Ham YM, Chun KH, Choi JS, Kim DH, Lee SK (2003) SEK1dependent JNK1 activation prolongs cell survival during G-Rh2induced apoptosis. Biochem Biophys Res Commun 304:358-364

Ham YM, Lim JH, Na HK, Choi JS, Park BD, Yim H, Lee SK (2006) Ginsenoside-Rh2-induced mitochondrial depolarization and apoptosis are associated with reactive oxygen species- and $\mathrm{Ca}^{2+}$-mediated c-Jun NH2-terminal kinase 1 activation in HeLa cells. J Pharmacol Exp Ther 319:1276-1285

Hengartner MO (2000) The biochemistry of apoptosis. Nature 407:770-776

Jin YH, Yoo KJ, Lee YH, Lee SK (2000) Caspase 3-mediated cleavage of p21WAF1/CIP1 associated with the cyclin A-cyclindependent kinase 2 complex is a prerequisite for apoptosis in SKHEP-1 cells. J Biol Chem 275:30256-30263

Kawamata H, Omotehara F, Nakashiro K, Uchida D, Shinagawa Y, Tachibana M, Imai Y, Fujimori T (2007) Oncogenic mutation of the p53 gene derived from head and neck cancer prevents cells from undergoing apoptosis after DNA damage. Int J Oncol 30:1089-1097

Kim YS, Jin SH (2004) Ginsenoside Rh2 induces apoptosis via activation of caspase- 1 and -3 and up-regulation of Bax in human neuroblastoma. Arch Pharm Res 27:834-839

Kim YS, Jin SH, Lee YH, Park JD, Kim SI (2000) Differential expression of protein kinase $C$ subtypes during Ginsenoside Rh2-induced apoptosis in SK-N-BE(2) and C6Bu-1 cells. Arch Pharm Res 23:518-524

Kim SY, Kim DH, Han SJ, Hyun JW, Kim HS (2007) Repression of matrix metalloproteinase gene expression by Ginsenoside Rh2 in human astroglioma cells. Biochem Pharmacol 74:1642-1651
Li Y, He K, Huang YH, Zheng DX, Gao C, Cui L, Jin YH (2010) Betulin induces mitochondrial cytochrome $\mathrm{c}$ release associated apoptosis in human cancer cells. Mol Carcinog 49:630-640

Li B, Zhao J, Wang CZ, Searle J, He TC, Yuan CS, Du W (2011a) Ginsenoside Rh2 induces apoptosis and paraptosis-like cell death in colorectal cancer cells through activation of p53. Cancer Lett 301:185-192

Li Q, Li Y, Wang XY, Fang XX, He K, Guo XX, Zhan Z, Sun C, Jin YH (2011b) Co-treatment with Ginsenoside Rh2 and betulinic acid synergistically induces apoptosis in human cancer cells in association with enhanced capsase- 8 activation, Bax translocation, and cytochrome C release. Mol Carcinog 50:760-769

Liu FS (2009) Mechanisms of chemotherapeutic drug resistance in cancer therapy-a quick review. Taiwan J Obstet Gynecol 48:239-244

Müller M, Wilder S, Bannasch D, Israeli D, Lehlbach K, Li-Weber M, Friedman SL, Galle PR, Stremmel W, Oren M, Krammer PH (1998) p53 activates the CD95 (APO-1/Fas) gene in response to DNA damage by anticancer drugs. J Exp Med 188:2033-2045

Nagata S (1999) Fas ligand-induced apoptosis. Annu Rev Genet 33:29-55

Nigro JM, Baker SJ, Preisinger AC, Jessup JM, Hostetter R, Cleary K, Bigner SH, Davidson N, Baylin S, Devilee P (1989) Mutations in the p53 gene occur in diverse human tumour types. Nature 342:705-708

Odashima S, Ohta T, Kohno H, Matsuda T, Kitagawa I, Abe H, Arichi S (1985) Control of phenotypic expression of cultured B16 melanoma cells by plant glycosides. Cancer Res 45:27812784

Oh JI, Chun KH, Joo SH, Oh YT, Lee SK (2005) Caspase-3dependent protein kinase $\mathrm{C}$ delta activity is required for the progression of Ginsenoside-Rh2-induced apoptosis in SK-HEP-1 cells. Cancer Lett 230:228-238

Owen-Schaub LB, Zhang W, Cusack JC, Angelo LS, Santee SM, Fujiwara T, Roth JA, Deisseroth AB, Zhang WW, Kruzel E (1995) Wild-type human p53 and a temperature-sensitive mutant induce Fas/APO-1 expression. Mol Cell Biol 15:3032-3040

Peter ME, Legembre P, Barnhart BC (2005) Does CD95 have tumor promoting activities? Biochim Biophys Acta 1755:25-36

Schilling T, Schleithoff ES, Kairat A, Melino G, Stremmel W, Oren M, Krammer PH, Muller M (2009) Active transcription of the human FAS/CD95/TNFRSF6 gene involves the p53 family. Biochem Biophys Res Commun 387:399-404

Strasser A, Jost PJ, Nagata S (2009) The many roles of FAS receptor signaling in the immune system. Immunity 30:180-192

Takahashi R (1997) Role of p53 tumor suppressor gene and Fas/ Apo-1 in induction of apoptosis and differentiation of cancer cells. Leukemia 11:3331-3333

van Loo G, Saelens X, van Gurp M, MacFarlane M, Martin SJ, Vandenabeele $P$ (2002) The role of mitochondrial factors in apoptosis: a Russian roulette with more than one bullet. Cell Death Differ 9:1031-1042

Wong RS (2011) Apoptosis in cancer: from pathogenesis to treatment. J Exp Clin Cancer Res 30:87

Xie X, Eberding A, Madera C, Fazli L, Jia W, Goldenberg L, Gleave M, Guns ES (2006) Rh2 synergistically enhances paclitaxel or mitoxantrone in prostate cancer models. J Urol 175:1926-1931 
Yi JS, Choo HJ, Cho BR, Kim HM, Kim YN, Ham YM, Ko YG (2009) Ginsenoside Rh2 induces ligand-independent Fas activation via lipid raft disruption. Biochem Biophys Res Commun 385:154-159

Zalcenstein A, Stambolsky P, Weisz L, Muller M, Wallach D, Goncharov TM, Krammer PH, Rotter V, Oren M (2003) Mutant p53 gain of function: repression of CD95(Fas/APO-1) gene expression by tumor-associated p53 mutants. Oncogene 22:5667-5676

Zhou M, Gu L, Yeager AM, Findley HW (1998) Sensitivity to Fasmediated apoptosis in pediatric acute lymphoblastic leukemia is associated with a mutant p53 phenotype and absence of Bcl-2 expression. Leukemia 12:1756-1763 